\title{
Questes
}

vestes Revue pluridisciplinaire d'études médiévales

\section{L'Erreur, l'échec, la faute : conclusions}

\section{Florian Besson et Catherine Kikuchi}

\section{(2) OpenEdition}

\section{Journals}

\section{Édition électronique}

URL : http://journals.openedition.org/questes/4219

DOI : 10.4000/questes.4219

ISSN : 2109-9472

\section{Éditeur}

Les Amis de Questes

\section{Édition imprimée}

Date de publication : 30 octobre 2015

Pagination : 141-144

ISSN : 2102-7188

\section{Référence électronique}

Florian Besson et Catherine Kikuchi, «L'Erreur, l'échec, la faute : conclusions », Questes [En ligne], 30 | 2015, mis en ligne le 01 novembre 2015, consulté le 15 septembre 2020. URL : http:// journals.openedition.org/questes/4219 


\section{Conclusions}

\section{Florian BESSON et Catherine KIKUCHI}

Université Paris-Sorbonne

Les séances de ce séminaire ont montré la diversité des conceptions de l'erreur, de l'échec et de la faute dans la société, la littérature et l'art du Moyen Âge occidental, ainsi que les différentes réactions des contemporains. La variété et la qualité des interventions nous ont permis d'aborder de multiples aspects de la question, grâce à l'interdisciplinarité et aux questionnements croisés qui ont également caractérisé les discussions qui ont suivi les séminaires et dont cette publication ne garde qu'imparfaitement la trace. Mais quoi qu'il en soit, toutes les contributions qui sont présentées ici sont révélatrices d'une manière médiévale de percevoir la société et les valeurs qui la traversent, en même temps qu'elles traduisent un certain état de la recherche sur la question dans nos disciplines. Les trois termes qui constituaient notre thème, l'erreur, l'échec et la faute, nous ont permis d'observer de nombreuses nuances dans leur appréhension et leur définition.

Nous avons d'abord pu constater le glissement fréquent de l'erreur vers la faute à portée morale ou religieuse, ce qui nous entraîne à être particulièrement attentifs aux changements de sens et aux évolutions diachroniques, en ce qui concerne le vocabulaire comme les phénomènes de société. La sorcellerie, étudiée par Aurélie Dumoulin en est sans doute l'exemple le plus flagrant, puisque d'une erreur légère, inspirée par des perceptions trompeuses, on passe à une faute impardonnable qui conduit 
au bûcher ${ }^{1}$. Le passage par l'erreur est somme toute assez peu fréquent, tout faux pas étant rapidement rapporté à une faute d'une nature plus élevée. En effet l'erreur et l'échec doivent être expliqués et justifiés. La trahison qui se noue autour du Coup de Melun représente bien la faute suprême qu'un vassal peut commettre envers son suzerain $^{2}$; le caractère perfide de l'empereur byzantin dans les sources de la première croisade est de même rapporté à une faute morale, qui repose pourtant en partie sur des erreurs d'appréciations et de perception entre les deux parties ${ }^{3}$.

Ces aspects nous ont permis de réfléchir à la manière dont les hommes du Moyen Âge percevaient la faute morale et au sens qu'ils lui accordaient. Les sermons de Jean Gerson ont ainsi permis d'appréhender la manière concrète dont le prédicateur mettait en scène la faute à travers la forme oratoire scolastique, dans un cadre culturel spécifique qui a pour but de rappeler la morale aux chrétiens, sans pour autant délaisser la sensibilité esthétique ${ }^{4}$. La faute doit être prêchée pour être évitée; elle doit être châtiée quand elle se produit, à l'image du châtiment dégradant que subissent les traîtres de Melun ${ }^{5}$ ou du châtiment divin que représente la naissance de Robert le Diable, suite à la faute de ses parents ${ }^{6}$; elle doit dans tous les cas être réprouvée, pour permettre aux auteurs de tirer des leçons sur l'avenir ou de mettre en valeur le bien, la voie droite.

En ce sens, on peut trouver différents traitements de la faute comme de l'échec dans les interventions qui ont été proposées dans ce séminaire. La faute morale comme l'échec peuvent être la source d'un renouveau : ainsi, les cruautés auxquelles se livre Robert le Diable dans sa jeunesse sont le point de départ de son rachat final, et la faute de ses

\footnotetext{
${ }^{1}$ Voir l'article d'Aurélie Dumoulin dans ce volume, p. 97-111.

${ }^{2}$ Voir l'article de Damien Varenne dans ce volume, p. 33-47.

${ }^{3}$ Voir l'article d'Annabelle Marin dans ce volume, p. 113-126.

${ }^{4}$ Voir l'article de Viviane Griveau-Genest dans ce volume, p. 81-95.

${ }^{5}$ Voir l'article de Damien Varenne, art. cit.

${ }^{6}$ Voir l'article d'Ismérie Triquet dans ce volume, p. 49-66.
} 
parents sert de pendant à l'avènement de la nouvelle dynastie des ducs de Normandie $^{7}$. De même, la bataille de Nicopolis devient un échec glorieux, fondateur du pouvoir et du prestige de la cour de Bourgogne, notamment grâce à l'œuvre de Jean Froissart ${ }^{8}$. Les fautes peuvent donc être portées au rang de mythe, comme elles le sont dans le cas des trois fautes d'Hector: les fautes qu'il commet sont excusables, puisqu'il est l'un des Neuf Preux et elles sont mêmes constitutives de son héroïsme. La chute de Troie elle-même est, à travers Enée, la condition de la fondation de Rome, et, à travers Francion, de la France. L'échec et l'erreur sonnent ici comme une épreuve du feu, permettant l'élimination des scories pour mieux forger la suite de l'histoire.

Reste cependant que ce sont les fautes d'Hector qui entraînent la chute de Troie et sa destruction. De la même façon, la perfidie de l'empereur Alexis entraînera selon Guillaume de Tyr l'échec des croisades postérieures et donc, à terme, la chute du royaume de Jérusalem $^{9}$. Il y a donc un deuxième traitement de la faute et de l'erreur : elles peuvent entraîner la fin, conduire à la perte. Les cités ne renaissent pas toujours de leurs cendres, et les héros n'ont pas toujours une deuxième chance.

Ces deux aspects ne sont pourtant pas contradictoires: ils s'inscrivent dans une lecture biblique de l'histoire. Adam et Eve ont commis le Péché originel, qui a amené la faute et la mort sur le genre humain; cependant, le sacrifice du Christ sur la croix est porteur de renouveau, car il sauve l'humanité par son Incarnation et sa Passion. Autrement dit, la faute et l'erreur sont caractéristiques du genre humain ; mais l'homme peut se racheter, et, dans les ruines de ses échecs,

\footnotetext{
${ }^{7}$ Ibid.

${ }^{8}$ Voir l'article de Marie-Gaëtane Martenet dans ce volume, p. 127-141.

${ }^{9}$ Voir l'article d'Annabelle Marin, art. cit.
} 
reconstruire. Travailler sur l'échec, l'erreur, la faute, c'est ainsi se pencher sur l'un des axes qui structure en profondeur la lecture ecclésiale du monde. C'est donc, puisque l'Ecclesia est au cœur du Moyen Âge ${ }^{10}$, toucher du doigt l'essence même de cette époque.

${ }^{10}$ Voir Joseph Morsel, L'Histoire (du Moyen Âge) est un sport de combat... Réflexions sur les finalités de l'histoire du Moyen Äge destinées à une société dans laquelle même les étudiants d'histoire s'interrogent, Paris, LAMOP, 2007, texte disponible en ligne : lamop.univ-paris1.fr/IMG/pdf/SportdecombatMac.pdf. 